\title{
What Does It Take? California County Funding Requests for Recovery-Oriented Full Service Partnerships Under the Mental Health Services Act
}

\author{
Mistique C. Felton · Cheryl E. Cashin • \\ Timothy T. Brown
}

Received: 29 August 2008/Accepted: 8 April 2010/Published online: 4 May 2010

(C) The Author(s) 2010. This article is published with open access at Springerlink.com

\begin{abstract}
The need to move mental health systems toward more recovery-oriented treatment modes is well established. Progress has been made to define needed changes but evidence is lacking about the resources required to implement them. The Mental Health Services Act (MHSA) in California was designed to implement more recovery-oriented treatment modes. We use data from county funding requests and annual updates to examine how counties budgeted for recovery-oriented programs targeted to different age groups under MHSA. Findings indicate that initial per-client budgeting for Full Services Partnerships under MHSA was maintained in future cycles and counties budgeted less per client for children. With this analysis, we begin to benchmark resource allocation for programs that are intended to be recovery-oriented, which should be evaluated against appropriate outcome measures in the future to determine the degree of recoveryorientation.
\end{abstract}

Keywords Recovery-oriented programs · Funding · Resource allocation - Mental health services act . Children

\section{Introduction}

The concept of recovery increasingly is guiding policies and practices in mental health systems in US states, as well as in other countries, such as Canada and New Zealand

M. C. Felton $(\bowtie) \cdot$ C. E. Cashin · T. T. Brown

Nicholas C. Petris Center on Health Care Markets and Consumer

Welfare at the University of California, 50 University Hall,

MC7360, Berkeley, CA 94720, USA

e-mail: mistique@petris.org
(Farkas 2007). The final report of the President's New Freedom Commission on Mental Health calls for fundamental reform of state mental health systems to be more consumer and family centered and recovery oriented in their care and services (New Freedom Commission 2003). The State of California has embraced the recovery philosophy and, in November of 2004, initiated a significant alteration of the state's city- and county-operated mental health systems with the passage of Proposition 63, which later became the Mental Health Services Act (MHSA).

There is an emerging consensus on the types of services that should be available in a recovery-oriented system and how they should be delivered (Institute of Medicine 2006; Farkas et al. 2005; Sowers 2005; New Freedom Commission 2003). A recovery-oriented system is grounded in the belief that recovery is a possible and expected outcome of treatment, and that the full range of comprehensive services and supports that an individual needs to meet his or her recovery goals be accessible, flexible, individualized and coordinated. Services are to be respectful of racial, cultural, and gender differences, and consumers should be involved in the planning, delivery, and evaluation of services (National Governor's Association webcast briefing document 2007). In their 3-year plans submitted to the State Department of Mental Health (DMH) to receive funds for Community Services and Supports under MHSA, these principles were translated into comprehensive "Full Service Partnership" programs to do "whatever it takes" to partner with consumers and families to meet individual recovery goals (Cashin et al. 2008).

Significant progress has been made to better define the concept of recovery and what it means for systems and services. This advancement has not been matched, however, with a full understanding of the budgeted resources required to successfully implement programs that are 
recovery oriented in their content and process, and that achieve recovery-oriented outcomes. Some guidance on the magnitude of the per-client budgets required to implement recovery-oriented programs may be found by examining the per-client costs for similarly intensive, though not explicitly recovery-oriented, programs. For example, there is a significant body of literature that examines the costs and cost-effectiveness of Assertive Community Treatment (ACT) programs (Latimer 2005; The Lewin Group 2000; Essock et al. 1998; Bond et al. 1990). Based on this literature, the Substance Abuse and Mental Health Services Administration (SAMHSA) estimates that ACT programs required between $\$ 9,000$ and $\$ 12,000$ per client per year in 2005, excluding the costs of housing and hospital stays (SAMHSA 2005). This estimate is based on resources required to achieve high fidelity to the ACT model, however, and is not necessarily directly linked to outcomes achieved. $^{1}$

California's Full Service Partnership (FSP) programs are modeled after the state's experience with pilot recoveryoriented programs targeted to homeless individuals with serious mental illness (known as AB2034 programs). AB2034 and FSP programs are considered to be a modified version of ACT, as they provide individualized integrated services, flexible funding, intensive case management, and $24 \mathrm{~h}$ access to care, which are common features of ACT programs. AB2034 and FSPs extend the ACT model, however, which has the main goal of reducing inpatient recidivism, ${ }^{2}$ by explicitly stating the goal of supporting recovery for enrolled consumers. (Spaite and Davis 2005). Other differences include a focus on housing in all programs, an explicit client-driven and recovery-oriented focus, and flexible funding for other supports, such as transportation and child care. In addition, the state regulations for FSP require that all program participation be voluntary and mandate a focus on providing the services that assist clients in the development and advancement toward goals (California Code of Regulations. Mental Health Services Act 2010).

Although there are some benchmarks for funding ACT programs, as noted above, California counties were required to develop program and expenditure plans for new FSP programs in the absence of adequate evidence to guide

\footnotetext{
${ }^{1}$ Other research, however, does indicate that relatively high-fidelity ACT programs achieve the intended outcomes of reduced hospitalization, with as much as a $78 \%$ reduction in hospital days (Latimer 1999).

2 The objectives of individual ACT programs and the outcome measures used to evaluate them may vary significantly, however. The Lewin Group (2000) found that research on ACT models has incorporated a variety of outcome measures, such as hospitalization rates, assessments of social functioning, housing stability, medication compliance, symptoms, time spent in jail, quality of life, substance abuse, and cost.
}

the estimation of resource requirements for programs intended to promote recovery and resilience. In addition, while ACT and AB2034 programs are designed to serve adult consumers, FSP programs extend this model to children and transition-age youth (ages 16-25). There is little evidence about the resource requirements for programs to promote resilience and recovery in these age groups.

This paper aims to begin remedying this situation. It is the companion piece to a previously-published study on MHSA plans for recovery-oriented services in California county departments of mental health. (Cashin et al. 2008). This companion study analyzed the comprehensiveness of FSP programs across eight recovery-oriented services, as well as the specific strategies employed for peer support, community collaboration and cultural competency. The results of this study showed that most FSP programs planned to offer comprehensive services as recommended by the American Association of Community Psychiatrists (AACP) guidelines for recovery-oriented services (Sowers 2005).

In this study, we examine how California counties' funding allocation changed after two years of experience with MHSA, and specifically how their budgeting for Full Service Partnership programs targeted to different age groups changed over time. We also explore whether counties with previous experience implementing recoveryoriented AB2034 programs budgeted for FSPs differently than counties with no previous experience with recoveryoriented programs.

\section{California's Mental Health Services Act}

The Mental Health Services Act was a ballot initiative (Proposition 63) passed in 2004 that set a one percent tax on adjusted gross incomes above $\$ 1$ million. This money is to be used by county mental health departments to provide new and innovative mental health services with a more recovery and consumer-driven focus. MHSA divided this tax revenue into five main funding categories: Community Services and Supports, Workforce, Education and Training, Capital Facilities and Information Technology, Prevention and Early Intervention, and Innovation. The Community Services and Supports (CSS) portion is to be used for service delivery enhancement, direct service provision, and outreach to bring previously unserved or underserved consumers into the system. There are three program categories that can be funded through CSS: full service partnerships (FSP), system development, and outreach and engagement (DMH 2005).

Full service partnerships's use a team approach to provide comprehensive, community-based psychiatric treatment, rehabilitation, and support for "whatever it takes" to 
move toward recovery and resilience for target populations. Individuals enrolled in FSPs are assigned a personal service coordinator who coordinates necessary services and supports $24 \mathrm{~h}$ a day, seven days a week. FSPs may provide housing, employment, peer support, wellness centers, crisis stabilization, food, clothing, respite care and other services necessary to meet individual recovery goals (MHSA Expenditure Report Fiscal Year, 2005-2006). The DMH has specified that at least $51 \%$ of CSS funds must be used for FSP programs. Small counties were exempt from this requirement for the first two years.

The admission criteria for FSP programs require an individual have a serious mental illness (or in children a serious emotional disturbance) and be currently unserved or underserved. The definition of underserved is extremely broad, including anyone who does not receive services to support their wellness, recovery or resilience (California Code of Regulations. Mental Health Services Act 2010). In addition to having a serious mental illness and being unserved or underserved, participants must meet one of the following criteria including: homelessness, at risk of homelessness, involvement or at risk of involvement with the criminal justice system, at risk of institutionalization, frequent users hospitals and/or emergency room treatment for mental health care, or for transition age youth, aging out of the child and youth mental health system, child welfare system or juvenile justice system (California Code of Regulations. Mental Health Services Act 2010). Figure 1 presents the criteria for adult entry into FSP. See the California Code of Regulations for additional information (California Code of Regulations. Mental Health Services Act 2010).
Currently, MHSA is only budgeted to provide intensive FSP services to $10-15 \%$ of clients in the public mental health system, which necessarily limits access to these services. To help remedy this, there has been some discussion of creating levels of FSP services so that as individuals begin to recover and are more able to manage their illness independently, they can receive a lower level of services, freeing up funds for more individuals, including more of the underserved, to receive the types of intensive services provided by FSPs (Abbott et al. 2009; Adult Systems of Care Committee 2008).

System development funds are to be used for programs that will affect all mental health clients, while outreach and engagement funds are to be used to bring the unserved and underserved, particularly racial/ethnic groups into the mental health system. MHSA also defines four age groups that must be addressed in the county CSS plans: children and youth, transition age youth (age 16-25), adults and older adults (age 60 and over).

To receive CSS funds, each county was required to submit a 3-year plan that addressed both children and adult systems of care, subject to guidelines and approval by the State Department of Mental Health (DMH) (MHSA Expenditure Report Fiscal Year 2005-2006, 2005). DMH also provided guidelines and a small amount of funding for required county-level planning processes. The planning guidelines specified that consumers and family members must be included in the process, particularly people who were previously unserved or underserved, and those who are not part of any formal advocacy group. The counties also were required to include representatives from relevant agencies, including law enforcement, education, and social
Fig. 1 FSP criteria for adults. Petris Center Analysis of the California Code of Regulations. Mental Health Services Act 2010




services (Program Expenditure Plan Requirements 2005). The stakeholder process involved topic-specific workgroups, the development of publicly available discussion documents, and general stakeholder meetings. It is estimated that over 100,000 stakeholders participated across the state (MHSA Fact Sheet 2007). By January 2009, all 58 California counties had submitted CSS plans, and these plans had been approved by the DMH (MHSA community services and supports plan approval status 2009). In addition, counties who received funding were required to provide the DMH with annual updates. The guidelines for the fiscal year 2008-209 update require a workplan listing, descriptions of new proposed programs, and documentation of a 30-day review process (Mayberg 2008). Forty-six counties submitted annual updates to DMH.

\section{Methods}

The study was conducted over the period September 2007 September 2009. Although the information used is publicly available, and therefore informed consent was not required, approval by the University of California, Berkeley Institutional Review Board for a broader study of MHSA implementation also covered this study. The data come from the program budgets submitted by 58 California counties in their 3-year CSS program and expenditure plans as well as the fiscal year 2008-09 annual updates. Any county that did not include data in both time frames was deleted for a final dataset with 40 of the 58 counties represented. The budget data were compiled by program category (FSP, system development, and outreach and engagement) and target age group (children, families and youth; transition-age youth; adults; older adults). Additional data were obtained from county reports on county mental health budgets and AB2034 expenditures per client for fiscal year 2003/04, prior to the implementation of MHSA.

The unit of analysis for this study is an individual program within the county plans $(N=654$ programs in 40 county plans, of which 265 programs are FSPs). The county plans were structured around programs, which we define as an integrated set of services, providers, outreach strategies, and treatment approaches designed to meet the specific needs and recovery/resilience goals of a target population. Counties could propose to initiate or expand multiple programs within their plans, and the number of programs per county ranged from 1 to 40 , with an average of 8 .

We computed per-client funding requests for full service partnership program by dividing the total program funding request by the specified program capacity (maximum number of clients that can be served by each program).
This computation yielded some per capita budget estimates that were considered to be outliers. Programs with per capita budgets computed to be less than $\$ 1,000$ or greater than $\$ 36,000$ were eliminated from the analysis and were assumed to be errors in the data. A total of 50 out of 265 programs were eliminated as outliers. Resource allocation patterns were examined using comparison of means, and a simple county fixed effects ordinary least squares regression model to examine significant differences in resource allocation across age groups. All dollars are reported in constant 2008 dollars.

\section{Results}

Overall Resource Allocation

The annual average funding request for fiscal year 2006-07 was $\$ 7,125,000$. The amount of funding requested two years later in the annual update of fiscal year 2008-09 was almost twice the initial funding request $(\$ 13,825,000$ per county). The annual request in fiscal year 2006-07 averaged $9.2 \%$ of the total county mental health budget in fiscal year 2003/04 prior to the implementation of MHSA (Table 1). The annual request in fiscal year 2008-09 became a larger portion of the 2003-04 budget, increasing to $17.9 \%$ of the 2003-04 fiscal year budget. Not surprisingly, CSS funds are proportionately larger for small counties in fiscal year 2008-09, as the increase in amount of funding available was greater for small counties than for medium and large counties. Those with a population less than 200,000 had an average annual funding request that was $23.4 \%$ of the 2003-04 county mental health budget in fiscal year 2008-09. The maximum amount of funds counties could request under MHSA was determined by a state-specified formula projecting the county's needs. Needs were determined by a combination of the county's share of the state population, the number of households in the county with incomes below $200 \%$ of the poverty line, the size of the uninsured population, and the prevalence of mental illness in the county. Adjustments were made to the formula to account for additional resources available to the county (DMH 2005). The funding formula for fiscal year 2008-2009 is based on the previously-used methodology, updated with the most current data from national and state databases.

Although the level of new funds brought into the system by MHSA appears to be small relative to existing budgets, these new resources are being allocated in a way that is intended to be the force driving system change. As these funds become a larger part of the budget, change may occur even more rapidly. FSP eligibility requirements are designed to target clients who suffer from the most severe 
Table 1 Summary of county CSS funding requests (FY2006-07 and FY2008-09)

\begin{tabular}{|c|c|c|c|c|}
\hline & $\begin{array}{l}\text { All } \\
\text { counties }\end{array}$ & $\begin{array}{l}\text { Small } \\
\text { counties }\end{array}$ & $\begin{array}{l}\text { Medium } \\
\text { counties }\end{array}$ & $\begin{array}{l}\text { Large } \\
\text { counties }\end{array}$ \\
\hline Average FY2006-07 request as $\%$ of FY2003-04 county mental health budget & $9.2 \%$ & $10.1 \%$ & $6.7 \%$ & $10.4 \%$ \\
\hline$\%$ of total FY2006-07 funding request for full service partnership programs & $56.8 \%$ & $44.0 \%$ & $59.6 \%$ & $56.6 \%$ \\
\hline$\%$ of total FY2006-07 funding request for systems development & $36.8 \%$ & $35.3 \%$ & $31.5 \%$ & $38.7 \%$ \\
\hline$\%$ of total FY2006-07 funding request for outreach and engagement & $6.2 \%$ & $20.6 \%$ & $8.8 \%$ & $4.4 \%$ \\
\hline Total average annual county CSS funding request FY2006-07 & $\$ 7,125,000$ & $\$ 856,250$ & $\$ 3,917,647$ & $\$ 29,285,714$ \\
\hline Average FY2008-09 request as \% of FY2003-04 county mental health budget & $17.9 \%$ & $23.4 \%$ & $12.6 \%$ & $20.2 \%$ \\
\hline$\%$ of total FY2008-09 funding request for full service partnership programs & $53.2 \%$ & $60.4 \%$ & $54.3 \%$ & $52.1 \%$ \\
\hline$\%$ of total FY2008-09 funding request for systems development & $40.7 \%$ & $23.8 \%$ & $32.9 \%$ & $44.3 \%$ \\
\hline$\%$ of total FY2008-09 funding request for outreach and engagement & $6.2 \%$ & $15.7 \%$ & $12.6 \%$ & $3.4 \%$ \\
\hline Total average annual county CSS funding request FY2008-09 & $\$ 13,825,000$ & $\$ 1,987,500$ & $\$ 7,352,941$ & $\$ 56,714,286$ \\
\hline
\end{tabular}

Petris Center analysis of 40 County Community Services and Supports plans and annual updates

The totals in dollar rather than percentages are denoted in bold

consequences of untreated or undertreated mental illness and move these patients from inappropriate settings, such as jails, to more appropriate treatment settings. In addition, as counties plan to increase collaboration across agencies (Cashin et al. 2008), better and more efficient care may be available to all clients. The new funds are meant to bring new, previously unserved or underserved clients into the system and to serve them in a different way. Fifty-seven percent of funds were requested for FSP programs in fiscal year 2006-07 (Table 1), which is consistent with a statewide analysis reported by the DMH (Statistics and Data Analysis Analysis 2007). FSP funding is intended to create a critical mass of new services that could drive change in overall system. This approach to change has the risk, however, of creating a two-tiered system (Abbott et al. 2007). An inherent tension is created between what are perceived to be underfunded "old style" programs for existing clients and new "cadillac services" for new clients. To address this apparent imbalance, $36.8 \%$ of funds were requested for system development to enhance the core mental health service delivery system.

As counties acquired two years of experience with MHSA programs, FSP funding dropped slightly in fiscal year 2008-09 to $53.2 \%$ of the budget and system development funding increased to $40.7 \%$. The expansion of system development funds may represent the integration of new services available in FSPs, such as housing, employment, and peer support services, into the mainstream of the system and could be reflective of counties recognition of the benefits for clients when these types of services are available to all clients.

Finally, the counties requested $6.2 \%$ of funds for outreach and engagement to support innovative efforts to reach unserved or under-served consumers in fiscal year 2006-07, and this percentage of funds did not change in fiscal year 2008-09. In fiscal year 2006-07 small counties allocated the least amount of funds to FSP (44\%). This shows that small counties took advantage of the exemption from the requirement that more than half of CSS funds go toward FSPs. The higher percentage of funding dedicated to system development and outreach and engagement in small counties for fiscal year 2006-07 may reflect the special needs of small counties who may have higher implementation costs, more limited mental health services and supports, and higher transportation costs (Draft Mental Health Services Act (MHSA) in small counties. Implementation considerations for stakeholders 2005). By fiscal year 2008-09, however, small counties were allocating the largest amount of funds to FSPs and surpassing the requirements by allocating $60 \%$ to FSPs. In contrast, large and medium size counties are contributing a smaller percentage of funds to FSPs in fiscal year 2008-09 than in fiscal year 2006-07, although they are still meeting the requirement to allocate $51 \%$ of funds to FSP programs.

\section{Allocation of Funding Requests by Age Group}

The allocation of county funding requests in fiscal year 2006-07 by age group is shown in Fig. 2. Adults receive the highest allocation, with $44.8 \%$ of funds requested for programs targeted to adults. The share of funds requested for programs targeted to children, youth, and families and transition-age youth (TAY) was 20.7 and 20\%, respectively. About $15 \%$ of funds were requested for programs targeted to older adults. Based on the demographic structure of California's population, TAY receive a disproportionately higher share of funds relative to their share of the population (20\% of funds vs. $14.6 \%$ of the population), while children received a slightly lower proportion of funds ( $20.7 \%$ of funds vs. $23.8 \%$ of the population). Older adults are receiving approximately the same percentage of funds relative to their share of the population (14.6\% of funds vs. 


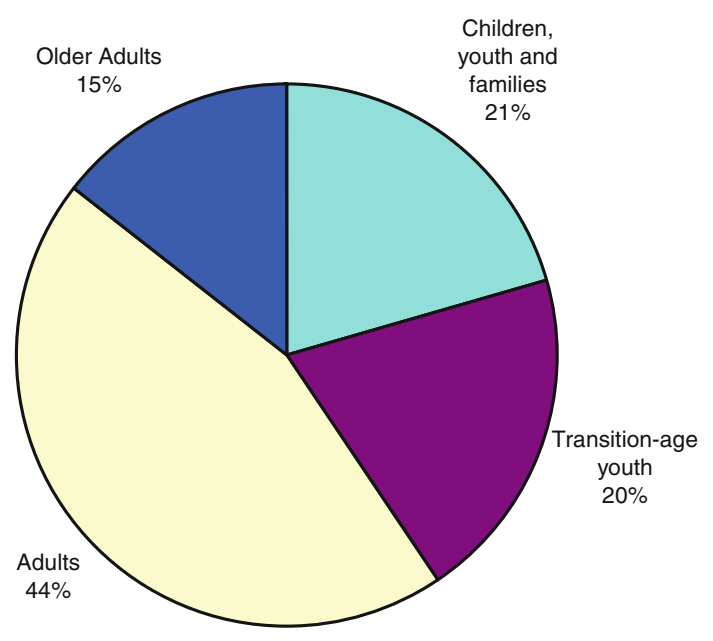

Fig. 2 Country funding requests by age group, 2006-07. Petris Center analysis of 40 County Community Services and Supports plans and annual updates

$14.8 \%$ of the population), while adults received slightly less than their share of the population $(44.8 \%$ of funds vs. $46.9 \%$ of the population). This distribution changed in fiscal year 2008-09 with $17.8 \%$ of funds dedicated to children, $15.2 \%$ of funds for TAY, $55.4 \%$ for adults and $11.6 \%$ for older adults (Fig. 3). Adults received a higher share of funds relative to their share of the population (55.4\% of funds vs. $46.4 \%$ of the population) while children received a lower share of funds relative to their share of the population $(17.8 \%$ of funds vs. $23.1 \%$ of the population). The distribution of funding requests by age group reflect both an attempt to bring historically unserved and underserved populations into the system, particularly TAY,

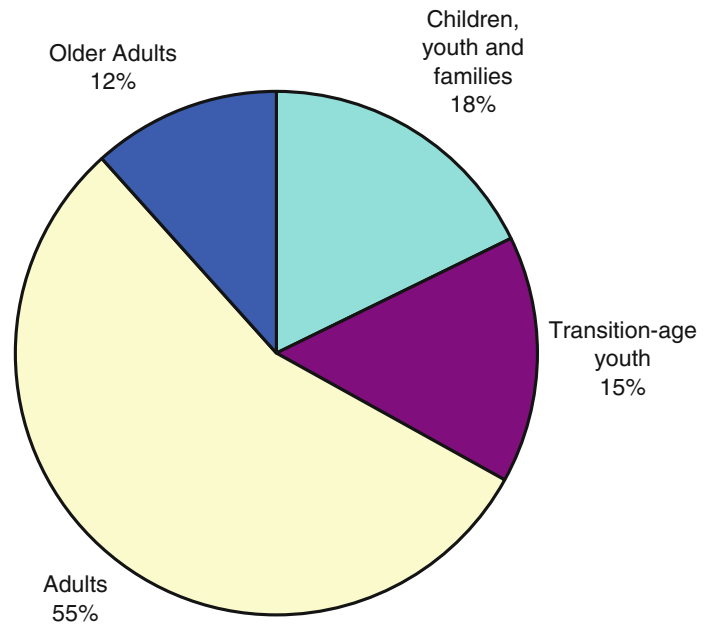

Fig. 3 Country funding requests by age group, 2008-09. Petris Center analysis of 40 County Community Services and Supports plans and annual updates as well as possible differences in the expected budgets needed to serve different populations, particularly children which will be discussed in more detail below.

\section{Per-Client Budgets for Full Service Partnerships:} What Does It Take?

Programs such as FSP that are intended to promote recovery may require higher levels of funding than even high-fidelity ACT programs because of higher expectations with regard to both the intended outcomes and the way services are delivered. Full service partnerships are expected to achieve recovery outcomes beyond reductions in hospital utilization, which may require additional services and supports. For example, a number of counties plan to include such supportive services as transportation, child care, assistance with benefits and entitlements, domestic violence screening and counseling, social and recreational activities, and parenting education (Cashin et al. 2008). The way recovery-oriented services are delivered also may create additional resource requirements. Because the programs should be flexible and person-centered, they may require more staff time and a wider range of approaches. In addition, resources should be available to support consumer participation in service planning, delivery and evaluation. However, any possible additional costs generated by the individualization of services in recovery-oriented care may be offset by the efficiencies gained through greater client collaboration and added self responsibility.

Nevertheless, the literature on ACT programs, as well as historical spending on AB2034 provide some basis for budgeting for FSPs, and it appears that counties took this into consideration while planning for these programs. The average FSP funding request per client in fiscal year 200607 was $\$ 12,192$, ranging from $\$ 1,141$ to $\$ 35,818$ (Table 2). This is consistent with per-client spending found in literature for ACT programs, the SAMHSA estimates of between $\$ 9,000-12,000$ per client per year, and with the average per-client expenditure on AB2034 programs in California's counties in 2003/04, which was $\$ 12,248$ (Davis et al. 2003). When adjusted for inflation, counties

Table 2 Average county per-client funding requests for FSP programs FY2006-07 and FY2008-09

\begin{tabular}{llll}
\hline Fiscal year & $\begin{array}{l}\text { \# of } \\
\text { programs }\end{array}$ & $\begin{array}{l}\text { Average per-client } \\
\text { funding (range) }\end{array}$ & $\begin{array}{l}\text { Standard } \\
\text { deviation }\end{array}$ \\
\hline FY2006-07 & 111 & $\begin{array}{l}\$ 12,192 \\
(\$ 1141-\$ 35818)\end{array}$ & 6,774 \\
FY2008-09 & 104 & $\begin{array}{l}\$ 14,601 \\
(\$ 1323-\$ 35660)\end{array}$ & 7,792 \\
\hline
\end{tabular}

Petris Center analysis of 40 County Community Services and Supports plans and annual updates 
Table 3 Fixed effects model of per capita funding request for FSP programs by age group

\begin{tabular}{|c|c|c|c|c|c|c|}
\hline Per Capita Funding & Coef. & Std. Err. & $\mathrm{t}$ & $\mathrm{P}>|\mathrm{t}|$ & [95\% Conf. Interval] & \\
\hline Children $^{a}$ & -3721.41 & 1308.92 & -2.84 & $0.005 * *$ & -6305.46 & -1137.36 \\
\hline TAY & -718.63 & 1161.11 & -0.62 & 0.537 & -3010.87 & 1573.61 \\
\hline Older adults & -1987.19 & 1237.45 & -1.61 & 0.110 & -4430.15 & 455.77 \\
\hline Adults (2008) & 2132.22 & 1503.73 & 1.42 & 0.158 & -836.41 & 5100.86 \\
\hline Children (2008) & -2074.47 & 1814.76 & -1.14 & 0.255 & -5657.15 & 1508.21 \\
\hline TAY (2008) & -593.63 & 1780.97 & -0.33 & 0.739 & -4109.59 & 2922.33 \\
\hline Older adults (2008) & 729.37 & 1843.80 & 0.40 & 0.693 & -2910.63 & 4369.36 \\
\hline \multirow[t]{5}{*}{ _cons } & 15063.79 & 1044.59 & 14.42 & 0.000 & 13001.57 & 17126.01 \\
\hline & & & & & Number of observations $(N)=$ & 215 \\
\hline & & & & & $\mathrm{F}(7,168)=$ & 4.76 \\
\hline & & & & & Prob $>F=$ & 0.0001 \\
\hline & & & & & Adj R-squared = & 0.3644 \\
\hline
\end{tabular}

Petris Center analysis of 40 County Community Services and Supports plans and annual updates

a Adults in 2006 is the omitted category

* Statistically significant at the 5\% level, two-tailed test

** Statistically significant at the $1 \%$ level, two-tailed test

actually spent less on FSPs than for AB2034 programs. Although the average FSP funding request per client in fiscal year 2008-09 appears to increase slightly to $\$ 14,601$, this difference is not statistically significant when controlling for county fixed effects (county fixed effects control for all non-time-varying characteristics of counties including their prior history) (Table 3 ). As clients move towards recovery and self-management, there may have been an expectation that the costs per client would decrease as time progresses. However, when the cost and effort involved in starting a new program, the expansion of these programs due to the availability of more funding, and the short time frame are factored in, the lack of decrease in cost per client over two years is unsurprising.

\section{Per Client Funding Requests by Age Group}

The funding requests show some statistically significant variation across programs targeted to specific age groups when we control for county fixed effects (Table 3). The average per-client funding request in fiscal year 2006-07 for programs targeted to transition-age youth, and older adults are not statistically different from adult FSPs. Spending in fiscal year 2008-09 remains statistically unchanged for TAY, adults, and older adults relative to fiscal year 2006-07. However, the average per-client funding request for children, families and youth is statistically lower than other age groups in fiscal year 2006-07 and remains statistically lower for fiscal year 2008-09. Counties are budgeting approximately $\$ 3700$ less per client for children than for other age groups.
The lower per-client funding requests for programs targeting children may be due to a number of factors. First, discussion at the Mental Health Services Oversight and Accountability Commission suggests that counties may have budgeted less for children because money from the Prevention and Early Intervention section of MHSA can be used to provide the extra funding to fully cover children and youth. These discussions may have influenced the decision to require $51 \%$ of funds in Prevention and Early Intervention be allocated to children, youth and families and transition-age youth ("Proposed guidelines prevention and early intervention component of the three-year program and expenditure plan", 2007). Other system factors may also be important. For example, the availability of matching funds from Medi-Cal (Medicaid) for adults and children may have also played a role, as some FSP services may be partially reimbursable by state and federal funds. For adults, Medi-Cal provides a 50\% match for qualified services. Children services however, can be funded through Early Prevention Screening Diagnosis and Treatment (EPSDT), where counties pay $10 \%$ of costs above a baseline expenditure level. Another possible explanation may be that children have other readily available funding sources that can be used to supplement their services. For example, funding from foster care can be used to provide in-home services that prevent the removal of children from their homes ("All county information notice no. I-28-99, children: Senate bill (sb) 163 wraparound services pilot ", 1999; "Children's wrap-around services." 1997). Nonetheless, ACT and AB2034 programs were designed primarily for adults, and the California counties are extending 
the model to children. It will be important to monitor the outcomes of these programs and whether adequate resources have been budgeted to meet the particular needs of children served by FSPs.

\section{Experience with Recovery-Oriented AB2034 Programs}

AB2034 programs were grants awarded by the state to 35 local mental health departments beginning in 1999. Evaluation of these programs shows that rates of homelessness, incarceration, hospitalization, and unemployment all decreased after these services were instituted and provided the impetus to the passage of MHSA and expanding these programs to all counties. For example, there was a $56 \%$ drop in the number of psychiatric hospital days, a $72 \%$ drop in the number of days incarcerated, a $67 \%$ drop in the number of homeless days and a $65 \%$ increase in full time employment for participants in the AB2034 programs (Davis et al. 2003). These programs were considered to be the model for FSPs, and because AB2034 programs had explicit recovery objectives, these programs may provide a better benchmark for budgeting for recovery-oriented FSP programs.

Table 4 shows the fiscal year 2006-07 budget per client in AB2034 programs compared to the FSPs budget per client in counties with and without AB2034 experience. Programs for children are excluded, since AB2034 programs were only available for adults. The average expenditure per client enrolled in AB2034 programs was $\$ 12,188$ in 2003/04. In counties with experience with AB2034 programs, there was a lower planned expenditure per client in FSPs than for AB2034 programs $(\$ 12,405$ for FSPs in fiscal year $2006-07$ vs. $\$ \$ 14,260$ in AB2034 programs). There is no statistical difference in the budget per client between counties with AB2034 programs and those without AB2034 programs in any year. However, in fiscal year 2008-09, counties without AB2034 experience budgeted about $\$ 4,000$ more per client than counties with AB2034 experience in programs targeted to multiple age groups, a statistically significant difference.

There are several possible explanations for the difference in per-client funding requests for FSP programs for multiple age groups between counties with and without AB2034 experience. First, there could be a systematic unobserved difference between those counties with and without AB2034 experience that is also correlated with per capita funding requirements to effectively run programs that are intended to be recovery-oriented. For example, FSP programs for multiple age groups in counties without AB2034 programs are more likely to be rural. Rural counties have unique challenges that may decrease effective service delivery. Rural counties are likely to have higher transportation costs as well as a more decentralized target population. In addition, rural areas are more likely to have shortages of qualified mental health providers which may drive up wages for available workers. Rural counties may also have higher start-up costs, as infrastructure may not be as well developed as in larger, more urban areas. There may also be economies of scale that rural counties are able to not take advantage of. Other differences between counties with and without AB2034 programs may include differences in staff composition and organizational culture as well as varying capacities to apply for and successfully receive outside funding (Brown et al. 2009).

\section{Discussion}

California is early in its implementation of MHSA-funded programs that are intended to be recovery-oriented. FSPs in particular, are intended to move California's mental health system towards significant change through the provision of comprehensive care across multiple agencies by increasing partnerships with law enforcement, education, social services as well as housing and employment agencies as well as the provision of services that are considered recoveryoriented by the American Association of Community Psychiatrists (Cashin et al. 2008). The flexible funding of MHSA allows for more seamless access to individualized care for mental health clients. While this does involve shifting some costs from hospitals and law enforcement to mental health, this is more suitable as it allows severely mentally ill people to receive more appropriate treatment in less restrictive settings. In addition, the increased capacity that MHSA has created for care after hospitalization or jail also creates more continuity of care. The flexible funding, increased capacity for seamless care and movement of care from hospitals and jails to more appropriate care in mental health under MHSA may be the start of system change. Examining whether the county allocation for these new resources vary over time gives some insight into the priority populations and services to be supported by the new funds. In addition, the analysis of funding requests for services under MHSA make it possible to begin to monitor whether the level of per capita resources budgeted for the new FSP programs and the relative allocations across age groups are sufficient to achieve the intended recovery outcomes.

The results of the analysis show that the per capita funding allocations for Full Service Partnership programs for adults are consistent with previous experience and funding benchmarks for ACT programs and California's recovery-oriented AB2034 programs. Although overall funding has doubled in the past two years, the budgeted funding per client has remained substantially the same, suggesting that counties' initial estimates for funding FSP 
Table 4 Average county funding requests for adult FSPs in counties with and without AB2034 experience

\begin{tabular}{|c|c|c|c|c|}
\hline Age group targeted & $\begin{array}{l}\text { \# of } \\
\text { programs }\end{array}$ & $\begin{array}{l}\text { Average per-client budget } \\
\text { for FSPs (range) }\end{array}$ & $\begin{array}{l}\text { Standard } \\
\text { deviation }\end{array}$ & $\begin{array}{l}\text { t-statistic } \\
(P \text {-value })^{\mathrm{a}}\end{array}$ \\
\hline $\begin{array}{l}\text { All programs (FY2006-07) in counties with AB2034 } \\
\text { experience }\end{array}$ & 77 & $\$ 12,405(\$ 1,141-\$ 35,818)$ & 6247 & $-0.5301(0.6032)$ \\
\hline $\begin{array}{l}\text { All programs (FY2006-07) in counties without AB2034 } \\
\text { experience }\end{array}$ & 15 & $\$ 13,833(\$ 1,694-\$ 27,871)$ & 10061 & \\
\hline $\begin{array}{l}\text { Programs for transition-age youth (FY2006-07) in counties } \\
\text { with AB2034 experience }\end{array}$ & 16 & $\$ 12,074(\$ 1,146-\$ 22,856)$ & 6229 & \\
\hline $\begin{array}{l}\text { Programs for transition-age youth (FY2006-07) in counties } \\
\text { without AB2034 experience }\end{array}$ & 0 & & & \\
\hline $\begin{array}{l}\text { Programs for adults (FY2006-07) in counties with } \\
\text { AB2034 experience }\end{array}$ & 16 & $\$ 15,586(\$ 8,471-\$ 35,818)$ & 6792 & $-0.52(0.6511)$ \\
\hline $\begin{array}{l}\text { Programs adults (FY2006-07) in counties without } \\
\text { AB2034 experience }\end{array}$ & 3 & $\$ 18,839(\$ 6,688-\$ 24,914)$ & 10523 & \\
\hline $\begin{array}{l}\text { Programs for older adults (FY2006-07) in counties with } \\
\text { AB2034 experience }\end{array}$ & 13 & $\$ 13,524(\$ 5,352-\$ 31,618)$ & 6831 & \\
\hline $\begin{array}{l}\text { Programs for older adults (FY2006-07) in counties without } \\
\text { AB2034 experience }\end{array}$ & 0 & & & \\
\hline $\begin{array}{l}\text { Programs for multiple age groups (FY2006-07) in counties } \\
\text { with AB2034 experience }\end{array}$ & 32 & $\$ 10,526(\$ 1,141-\$ 19,729)$ & 5204 & $-0.68(0.5094)$ \\
\hline $\begin{array}{l}\text { Programs for multiple age groups (FY2006-07) in counties } \\
\text { without AB2034 experience }\end{array}$ & 12 & $\$ 12,582(\$ 1,694-\$ 27,871)$ & 10008 & \\
\hline All programs (FY2006-07) & 92 & $\$ 12,638(\$ 1,141-\$ 35,818)$ & 6961 & \\
\hline All programs in counties with $\mathrm{AB} 2034$ experience & 66 & $\$ 14,895(\$ 1,323-\$ 34,740)$ & 7269 & $-0.9236(0.3626)$ \\
\hline Programs in counties without AB2034 experience & 23 & $\$ 16,860(\$ 2,199-\$ 35,660)$ & 9256 & \\
\hline $\begin{array}{l}\text { All programs for transition-age youth (FY2008-09) } \\
\text { in counties with AB2034 experience }\end{array}$ & 13 & $\$ 17,064(\$ 1,323-\$ 34,740)$ & 8754 & \\
\hline $\begin{array}{l}\text { All programs for transition-age youth (FY2008-09) in counties } \\
\text { without AB2034 experience }\end{array}$ & 1 & $\$ 18,055$ & & \\
\hline $\begin{array}{l}\text { Programs for adults (FY2008-09) in counties with AB2034 } \\
\text { experience }\end{array}$ & 16 & $\$ 18,535(\$ 6,174-\$ 32,928)$ & 6620 & \\
\hline $\begin{array}{l}\text { Programs for adults (FY2008-09) in counties without AB2034 } \\
\text { experience }\end{array}$ & 0 & & & \\
\hline $\begin{array}{l}\text { Programs for older adults (FY2008-09) in counties with } \\
\text { AB2034 experience }\end{array}$ & 11 & $\$ 15,355(\$ 5,108-\$ 31,215)$ & 7334 & \\
\hline $\begin{array}{l}\text { Programs for older adults (FY2008-09) in counties } \\
\text { without AB2034 experience }\end{array}$ & 1 & $\$ 35,660$ & & \\
\hline $\begin{array}{l}\text { Programs for multiple age groups (FY2008-09) in counties } \\
\text { with AB2034 experience }\end{array}$ & 26 & $\$ 11,377(\$ 1350-\$ 19662)$ & 5376 & $-2.09(0.045)^{*}$ \\
\hline $\begin{array}{l}\text { Programs for multiple age groups (FY2008-09) in counties } \\
\text { without AB2034 experience }\end{array}$ & 21 & $\$ 15,908(\$ 2,199-\$ 32,875)$ & 8692 & \\
\hline All programs (FY2008-09) & 89 & $\mathbf{\$ 1 5 , 4 0 3}(\$ 1,323-\$ 35,660)$ & 7823 & \\
\hline
\end{tabular}

Petris Center analysis of 40 County Community Services and Supports plans and annual updates; $F Y$ fiscal year

Programs targeted to children are excluded in this analysis

a To test significance of the difference between means of per capita FSP budgets for programs in counties with and without AB2034 experience

* Statistically significant at the $5 \%$ level, two-tailed test

The average for all programs rather than the subgroups listed above are denoted in bold

programs were within an appropriate range. In addition, funding for system development has, on average, increased slightly after two years, possibly indicating an attempt to bring new services provided through FSPs into the mainstream of the public mental health system. MHSA is changing the types of services available for clients at the margins through FSPs, while also introducing new services to the current system through system development funds. Successes of FSP programs may lead to the continued incorporation of additional services into usual care models, as seen through the expansion of system development funding. 
The results also show that California's counties have allocated less on both an aggregate and per capita basis for services for children, families and youth. There are a number of possible explanations for this observed allocation pattern, including the possibility of more opportunities to leverage other resources for children's services. Lastly, results comparing counties with AB2034 programs to counties that did not have AB2034 programs show that for programs that serve multiple age groups, budgeted funding is lower in fiscal year 2008-09 for counties that had AB2034 programs. This may be an indication that once counties have implemented programs with recovery-oriented services that efficiencies are gained more quickly when starting up new programs under MHSA.

Through the creation of FSPs, we can think of implementation as the start of 58 pilot programs in California counties. This allows for major problems and adaptations to occur before a larger roll out. There is concern that the current set of new programs may not be expanded and result in a two tiered system. However, there is evidence that using pilot programs can lead to the integration of new strategies into the traditional system. A number of states have used the mechanism of Medicaid waivers to pilot test and then expand new types of mental health programs. For example, in 2000, Florida began a consumer-directed care waiver program to allow long-term care patients to live in the community. The successes of this program led the state to expand this program throughout the state. In Oklahoma, a partial capitated financing system called SoonerChoice was implemented in 1995 in rural areas and was expanded to the entire state in 2004 (Verdier et al. 2009).

In order to know "what it takes" to achieve recovery outcomes for different populations, however, it must be possible to evaluate resource allocations against outcomes that are appropriate at both the system and program levels, and that are meaningful to individual consumers and family members. While previous analysis of county plans show the comprehensiveness of FSPs across eight recovery-oriented services, (Cashin et al. 2008), we do not know whether the provision of these services alone is enough to result in recovery. The stated goals of the MHSA legislation are to promote recovery and reduce the negative consequences of untreated mental illness, including suicide, incarcerations, school failure or drop-out, unemployment, prolonged suffering, homelessness, and removal of children from their homes (MHSA 2004). There are a number of recovery measures that are currently in use in some counties (e.g., Miller et al. 2009), and a basic statewide data system is now in place to track the progress of individual FSPs toward reducing adverse events among enrolled individuals. As of yet, however, there is not a clear system in place for monitoring the impact of MHSA, and FSP programs in particular, on recovery (Cashin et al.
2008). California has taken important steps to make resources available to transform the state's mental health services to support recovery for mental health consumers. There is an important opportunity to put monitoring systems in place to ensure that those resources are sufficient and efficiently used to change service delivery and support individual consumers to meet their recovery goals.

Acknowledgments This research was funded by the California HealthCare Foundation (Award \# 04-1618) and the National Institute of Mental Health (Mental Health Economics Training Program, Award \# T-32 MH070335). The authors thank Richard Scheffler, Leonard Miller, Neal Adams and Brent Fulton for insights and comments on earlier drafts of the paper. The authors also thank Tracy Finlayson for her work on the early research phase of this project, Bonnie Li for compiling and entering financial data from the county plans and Candy Pareja for her work on compiling, entering and analyzing the data.

Open Access This article is distributed under the terms of the Creative Commons Attribution Noncommercial License which permits any noncommercial use, distribution, and reproduction in any medium, provided the original author(s) and source are credited.

\section{References}

Abbott, B., Dhillon, M., Edmondson, D., Jordan, P., Lopez, R., Meisel, J., Milgrom, C., \& Vega, E. (2007). Mental health services act implementation study: Planning and early implementation of community services and supports in seven counties. In D. O. M. Health (Ed.) (pp. 70).

Abbott, B., Dhillon, M., Edmondson, D., Jordan, P., Lopez, R., Meisel, J., Milgrom, C., \& Vega, E. (2009). MHSA implementation study: Community services and supports successes and challenges. In D. O. M. Health. (Ed.) (Vol. 3, pp. 57).

Adult systems of care committee. (2008). California adult system of care committee recommended guidelines for levels of service: California Mental Health Directors Association.

All county information notice no. I-28-99, children: Senate bill (sb) 163 wraparound services pilot. (1999). In D. O. S. Services (Ed.) (pp. 45).

Assertive Community Treatment Association. http://www.actassociation. org/actmodel.

Bond, G., Witheridge, T., Dincin, J., Wasmer, D., Webb, J., \& GraafKaser, R. (1990). Assertive Community Treatment for frequent users of psychiatric hospitals in a large city: a controlled study. American Journal of Community Psychology, 18(6), 865-891.

Brown, T. T., Mahoney, C., Adams, N., Felton, M., Pareja, C. (2009) What Predicts Recovery Orientation in County Departments of Mental Health? A Pilot Study. Administration and Policy in Mental Health and Mental Health Services Research. 2009 November 4 [Epub ahead of print].

California Code of Regulations. Mental Health Services Act. (2010).

Cashin, C., Scheffler, R., Felton, M., Adams, N., \& Miller, L. (2008). Transformation of the California mental health system: Stakeholder-driven planning as a transformational activity. Psychiatric Services, 59(10), 1107-1114.

Children's wrap-around services., California State Senate 6 (1997).

Davis, G., Johnson, G., \& Mayberg, S. W. (2003). Effectiveness of integrated services for homeless adults with serious mental illness. In G. S. Office (Ed.) (pp. 1-108). 
Department of Mental Health (2007). Fact Sheet: Mental Health Services Act (Prop 63). Sacramento, CA, Oct 2007.

Department of Mental Health (DMH) (2005). Planning estimates for Mental Health Services Act Community Services and Supports. Letter \# 05-02. Sacramento, CA. June 1, 2005.

Draft Mental Health Services Act (2005) (MHSA) in small counties. Implementation considerations for stakeholders. (2005). In D. O. M. Health (Ed.) (pp. 7).

Essock, S. M., Frisman, L. K., \& Kontos, N. J. (1998). Costeffectiveness of assertive community treatment teams. American Journal of Orthopsychiatry, 68(2), 179-190.

Farkas, M. (2007). The vision of recovery today: What it is and what it means for services. World Psychiatry, 6(2), 4010.

Farkas, M., Gagne, C., Anthony, W., \& Chamberlin, J. (2005). Implementing recovery oriented evidence based programs: Identifying critical dimensions. Community Mental Health Journal, 41(2), 141-158.

Institute of Medicine. (2006). Improving the quality of health care for mental and substance-use conditions. Washington, DC: Committee on Crossing the Quality Chasm: Adaptation to Mental Health and Addictive Disorders.

Latimer, E. (1999). Economic impacts of assertive community treatment: A review of the literature. Canadian Journal of Psychiatry, 44, 443-454.

Latimer, E. (2005). Economic considerations associated with assertive community treatment and supported employment for people with severe mental illness. Journal of Psychiatry and Neuroscience, 30(5), 355-359.

Mayberg, S. (2008). DMH information notice \#: 08-10 community services and supports (CSS) plan update guidelines for fiscal year (FY) 2008/09. In C. D. O. M. Health (Ed.) (pp. 5).

Mental Health Services Act Expenditure Report Fiscal Year 20052006. A Report to the Legislature in Response to AB 131 Omnibus Health Budget Trailer Bill, Chapter 80, Statutes of 2005. Sacramento, CA, State of California, Department of Mental Health, Jan 2006 http://www.healthvote.org/uploads/ pdf/MHSA_Expenditure_Report.pdf.

Mental Health Services Act. State of California, 2004.

MHSA Community Services and Supports plan approval status. (2009) (January 21, 2009). Retrieved September, 21, 2009.

Miller, L., Brown, T. T., Pilon, D., Scheffler, R., Davis, M. (2009) "Patterns of Recovery from Severe Mental Illness: A Pilot Study of Outcomes.; Community Mental Health of Journal. doi: 10.1007/s10597-009-9211-x.
National Governor's Association, Center for Best Practices (2007). Briefing Document for Webcast: Transforming State Mental Health Systems: Addressing the Needs of Individuals and Planting the Seeds for Mental Health Transformation. May 10, 2007.

President's New Freedom Commission on Mental Health. (2003). Achieving the Promise: Transforming Mental Health Care in America. Final Report. Pub. No. SMA-03-3832. Rockville, MD: Department of Health and Human Services.

Program Expenditure Plan Requirements for Mental Health Services Act-Community Services and Supports. (2005) Sacramento, CA, State of California, Department of Mental Health, Aug 1, 2005.

Proposed guidelines prevention and early intervention component of the three-year program and expenditure plan. (2007). In D. O. M. Health (Ed.) (pp. 32).

Sowers, W. (2005). Transforming systems of care: The American association of community psychiatrists guidelines for recovery oriented services. Community Mental Health Journal, 41(6), 757-774.

Spaite, P. W., \& Davis, M. S. (2005). The mentally ill and the criminal justice system: A review of programs. Columbus: NAMI Ohio.

Statistics and Data Analysis Analysis. (2007). Mental health services act community services \& support three-year program and expenditure plan-fiscal year 2005/2006 through 2007/2008. In D. O. M. Health (Ed.) (pp. 1).

Substance Abuse and Mental Health Services Administration (2005). Evidence-based practices: Shaping mental health services toward recovery. Assertive Community Treatment. Information for Public Mental Health Authorities. Washington, D.C.: US Department of Health and Human Services. http://mental health.samhsa.gov/cmhs/communitysupport/toolkits/community/ ACTinfoPMHA.asp.

The Lewin Group (2000). Assertive Community Treatment Literature Review. Prepared for the Health Care Financing Administration and the Substance Abuse and Mental Health Services Administration.

Verdier, J., Colby, M., Lipson, D., Simon, S., Stone, C., Bell, T., Byrd, V., et al. (2009). Soonercare 1115 waiver evaluation: Final report. Washington, DC: Mathematica Policy Research, Inc. 